\title{
Caracterización MICROTOPOGRÁfICA E INFLUENCIA dE LAS COSTRAS BIOLÓGICAS EN LA RUGOSIDAD DEL SUELO EN EL CENTRO-OESTE de LA ARgentina
}

\author{
MICROTOPOGRAPHIC CHARACTERIZATION AND INFLUENCE OF BIOLOGICAL \\ SOIL CRUSTS ON THE ROUGHNESS OF THE SOIL IN THE CENTER-WEST OF \\ Argentina
}

\author{
Ana L. Navas Romero*1,2(D, Mario A. Herrera Moratta²,3, Eduardo Martínez \\ Carretero $^{2}$ (D) María C. Fernández Belmonte ${ }^{4}$ y María A. Duplancic ${ }^{2,5}$ (D)
}

\begin{abstract}
SUMmary
1. Instituto de Ingeniería QuímicaFacultad de Ingeniería. UNSJ-CONICET, San Juan, Argentina.

2. Grupo de Geobotánica y Fitogeografía. Instituto de Investigación en las Zonas Áridas (IADIZA)- CCT CONICET, Mendoza, Argentina.

3. Instituto de Biotecnología-Facultad de Ingeniería. UNSJ-CONICET, San Juan, Argentina.

4. Dpto. Ciencias AgropecuariasFacultad de Ingeniería y Ciencias Agropecuarias, UNSL. San Luis, Argentina.

5. Facultad de Ciencias Exactas y Naturales-UNCuyo. Mendoza, Argentina.

*analauranavas@gmail.com.ar

Citar este artículo

Background and aims: The influence of biological soil crusts (BSC) on soil roughness is an important function of these communities at the ecosystem level. Our objective was to characterize microtopographically the different types of BSC and evaluate their effect on the roughness of the soil along three systems differentiated by their degree of aridity.

M\&M: The microrelief and roughness were evaluated in three systems: semi-arid, arid, and hyper-arid; by different and complementary techniques: chain method, photographic analysis and technique of metal rods. For the first one, a block design was used, while for the other two, we worked on the types of dominant biological crusts in each system.

Results: The morphology of the BSC varied according to the type of dominant organism. The mosses had a low height and were classified as "gently undulating", the cyanobacteria had more abrupt peaks, and was classified as "pinnacled", and the lichens had two height frequencies and were classified as "rolling". The BSC influenced the roughness in the three sites evaluated. The type of BSC that dominated influenced the level of roughness found. The hyper-arid site was the site where the BSC had the most significant impact on roughness.

Conclusions: The microtopographic variations and the increase in roughness provided by the BSC is key to understanding the dynamics of the Monte because small interruptions on the soil such as those generated by the BSC could increase water availability and decrease nutrient losses by erosion, two fundamental aspects of the functioning of these fragile systems.
\end{abstract}

NAVASROMERO, A. L., M. A. HERRERA MORATTA, E. MARTÍNEZ CARRETERO, M. C. FERNÁNDEZ BELMONTE \& M. A. DUPLANCIC. 2019. Caracterización microtopográfica e influencia de las costras biológicas en la rugosidad del suelo en el centro-oeste de la Argentina. Bol. Soc. Argent. Bot. 54: 533-551.

DOI: http://dx.doi. org/10.31055/1851.2372.v54. n4.24163

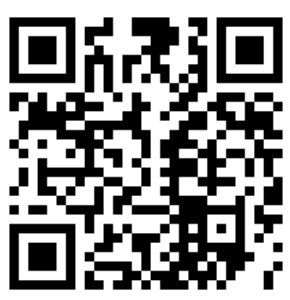

Recibido: 29 Abril 2019 Aceptado: 19 Septiembre 2019 Publicado: 15 Diciembre 2019 Editor: Ramiro Aguilar (D)

ISSN versión impresa 0373-580X ISSN versión on-line 1851-2372

\section{KEY WORDS}

Aridity, biological crusts, evapotranspiration, morphology, roughness.

\section{REsumen}

Introducción y objetivos: La influencia de las costras biológicas del suelo (CBS) en la rugosidad del suelo es una importante función de estas comunidades a nivel ecosistémico. Nuestros objetivos fueron caracterizar microtopográficamente los tipos de CBS y evaluar su efecto en la rugosidad del suelo en tres sistemas diferenciados por su grado de aridez.

M\&M: El microrelieve de las CBS y su influencia en la rugosidad se evaluaron en tres sistemas: semiárido, árido, e hiperárido; mediante técnicas diferentes y complementarias: método de la cadena, análisis fotográfico y técnica de las varillas metálicas. Para la primera se empleó un diseño en bloque, mientras que paras las otras dos se trabajó sobre los tipos de CBS dominantes en cada sistema.

Resultados: La morfología de las CBS varió según el tipo de organismo dominante. Los musgos tuvieron una baja altura clasificándose como "suavemente ondulados", las cianobacterias tuvieron picos más abruptos, clasificándose como "pinaculadas" y los líquenes tuvieron dos frecuencias de alturas clasificándose como "rodante". Las CBS influyeron en la rugosidad en los tres sitios evaluados. El sitio hiperárido fue donde tuvieron mayor impacto las CBS en la rugosidad. El tipo de CBS que dominó influyó en el nivel de rugosidad hallado.

Conclusiones: Las variaciones microtopográficas y el incremento en la rugosidad proporcionada por las CBS es clave en la dinámica del Monte debido a que pequeñas interrupciones sobre el terreno podrían incrementar la disponibilidad de agua y disminuir las pérdidas de nutrientes por erosión, dos aspectos fundamentales del funcionamiento de estos sistemas.

Palabras clave

Aridez, costras biológicas, evapotranspiración, morfología, relieve. 


\section{INTRODUCCIÓN}

Las costras biológicas del suelo (CBS) son comunidades de cianobacterias, algas, hongos, líquenes y musgos, unidos cohesivamente con partículas de suelo, que se desarrollan en varios milímetros a centímetros del perfil de la capa superior del suelo (Evans \& Johansen, 1999; Belnap, 2006; Belnap \& Lange, 2001; García-Pichel, 2003). Las CBS son componentes bióticos cruciales en ecosistemas secos en todo el mundo. Constituyen "mantos de fertilidad" (García-Pichel et al., 2003), funcionando como ingenieros del ecosistema (Jones et al., 1997; Bowker et al., 2005) suministrando servicios, como producción primaria, prevención de erosión del suelo, lixiviación de elementos (Belnap \& Lange, 2001; Beraldi Campesi et al., 2009), acondicionamiento del suelo, y fertilización del suelo con $\mathrm{C}$ y $\mathrm{N}$ recién fijados (Johnson et al., 2007).

Además de las funciones arriba mencionadas, las CBS, son una de las más importantes variables que influyen en la rugosidad de la superficie del suelo, cubriendo hasta el $70 \%$ de áreas entre plantas (Issa et al., 1999; Belnap et al., 2005). Las CBS aumentan la rugosidad de la superficie del suelo gracias a la presencia de sus organismos componentes en superficie y la hinchazón de estos. La rugosidad superficial del suelo es una variable importante que influye en los procesos de intercambio de materia y energía en las direcciones horizontal y vertical de la superficie terrestre. La microtopografía conferida por las CBS puede controlar la infiltración de la lluvia, la redistribución de la humedad del suelo, la retención de agua y reducir la cantidad de escorrentía (Govers \& Helming, 2000; Darboux et al., 2002; Antoine et al., 2009; Zheng et al., 2014). Además, las CBS permiten la formación de pequeños charcos en la superficie del suelo que aumentan la acumulación de polvo sedimentado, la capacidad de almacenamiento de agua y su tiempo de residencia (Rodríguez-Caballero et al., 2012; Williams et al., 2012).

En los ambientes semiáridos, áridos e hiperáridos, el régimen escaso, variable e impredecible de las precipitaciones sumado a la escasa cobertura vegetal convierten a la disponibilidad de agua y a la facilitación de nutrientes en los factores más importantes que limitan el funcionamiento del ecosistema (Noy-Meir, 1973). Así, pequeñas interrupciones sobre el terreno como las generadas por las CBS pueden tener profundos impactos en la dinámica ecosistémica.

El incremento en la rugosidad proporcionada por las CBS es clave para comprender la dinámica de los ecosistemas del Monte y fundamental en el contexto de la mayor fragilidad de estos sistemas. El control de la infiltración de la lluvia, la redistribución de la humedad del suelo, la retención de agua (Govers et al., 2000; Darboux et al., 2002; Antoine et al., 2009), la captación de polvos y nutrientes y la moderación de los procesos de escorrentía (Kidron, 2007), proporcionados por la rugosidad de las CBS, como consecuencia de un incremento en el relieve, podrían ser esenciales para el mantenimiento de los procesos ecológicos en los sistemas áridos.

La intensidad del efecto producido por el grupo de CBS dominantes en la rugosidad superficial de un sistema depende de tres factores: a macroescala, depende del clima dominante y a microescala de la composición específica (o estado de desarrollo) de la CBS y de la textura del suelo (Belnap \& Lange, 2003; Belnap, 2006; Chamizo et al., 2012; Rodríguez-Caballero et al., 2015). Las CBS afectan la rugosidad de la superficie del suelo a través de las diferencias en altura de las especies componentes (Evans \& Johansen, 1999). La rugosidad también puede variar según el estado sucesional de las CBS. En las CBS la sucesión inicia con el crecimiento de cianobacterias pioneras (claras) durante eventos episódicos de humedad disponible, posteriormente sucede el atrapamiento de partículas minerales gracias a la red de filamentos de las cianobacterias y a la matriz de limo extracelular (Belnap \& Lange, 2001; Zaady et al., 2010). Finalmente, el desarrollo sin perturbaciones conduce a múltiples ensamblajes de especies que albergan bacterias, arqueas, hongos, algas e incluso poblaciones de líquenes y musgos, formando una estructura más estable y definida (Nagy et al., 2005; Bates \& Garcia- Pichel, 2009). Así, comunidades de CBS dominadas por líquenes o musgos muestran una mayor rugosidad superficial que las dominadas por algas o cianobacterias (Belnap, 2006; Williams et al., 2012; RodríguezCaballero et al., 2015). La textura del suelo define qué especies pueden llegar a instalarse en un sistema. Suelos arcillosos y limosos permiten el establecimiento de musgos y líquenes, mientras que suelos arenosos sólo de cianobacterias. Por último, 


\section{A. L. Navas Romero et al. - Caracterización microtopográfica de las costras biológicas del suelo}

a escala regional, el régimen general de temperatura y precipitaciones limita la distribución de las especies componentes de las CBS, y por lo tanto es quien determina en primer lugar el microrrelieve dominante (Colesie et al., 2016).

Basados en esto último, Belnap \& Lange (2003) establecieron una clasificación general de la morfología de las CBS. Para ello se apoyaron en la relación entre el aspecto externo y la evapotranspiración potencial (ETP), reconociendo 4 tipos de CBS: lisas, rugosas, pinaculadas y rodantes. Las lisas son aquellas constituidas principalmente por cianobacterias, algas y hongos. En éstas, la superficie del suelo está formada por partículas minerales, comúnmente de arena, unidas por cianobacterias. Estas CBS dominan en regiones hiperáridas y áridas, con precipitaciones muy bajas y temperaturas muy altas, donde los suelos nunca se congelan. Como rugosas reconocieron a las constituidas principalmente por cianobacterias, algas y hongos con parches de líquenes y musgos. Dominan en regiones áridas y semiáridas con suelos que no se congelan y que poseen una ETP más baja que en las regiones con costras lisas. Como costras pinaculadas, a las constituidas principalmente por cianobacterias endémicas, pudiendo tener hasta un $40 \%$ de cobertura de líquenes y musgos. Estas costras se caracterizan por tener una fisonomía en forma de montículos pediculados que se forman a medida que los suelos se levantan por el deshielo y son erosionados por el agua pendiente abajo. Se encuentran en las latitudes medias de los desiertos más fríos donde las temperaturas de congelación son comunes y las raíces de plantas vasculares escasas (Ej. Meseta del Colorado). Es el tipo de costra más vulnerable a las perturbaciones. Por último, denominaron costras rodantes a las constituidas principalmente por líquenes y/o musgos y en algunos casos capas gruesas de cianobacterias. Se encuentran en ambientes con ETP más baja correspondiéndose con las zonas más frías. El aumento en grosor de la capa de CBS parece disminuir las bajas temperaturas subsuperficiales del suelo.

A pesar de que la rugosidad es un parámetro clave en diversos procesos (escorrentía, infiltración y redistribución de agua), a nivel mundial casi no existen estudios que cuantifiquen la rugosidad de la superficie del suelo en los suelos cubiertos por CBS. Las descripciones microtopográficas de las
CBS se han limitado a observaciones puntuales y a experiencias de campo, existiendo escasos trabajos que describen el microrrelieve generado por las CBS (Belnap \& Lange, 2003; Lan et al., 2012; Colesie et al., 2014). Esto sumado a que la mayoría de estos trabajos no realizaron descripciones de la microtopografía existente, sino más bien del efecto en factores funcionales, como erosión, hidrofobia, retención de agua (Kidron, 2007; Zheng et al., 2014; Rodríguez-Caballero et al., 2012; RodríguezCaballero et al., 2015). Nuestra hipótesis fue que las CBS modifican la rugosidad del suelo y que esta modificación varía con el grado creciente de aridez del sistema en el centro-oeste de la Argentina. Así el sistema hiperárido tendría una morfología lisa produciendo el menor impacto en el relieve. El sistema árido tendría una morfología rugosa ocasionando un impacto intermedio en el relieve. Finalmente, el sistema semiárido tendría una morfología intermedia entre rugosa y pinaculada generando el mayor impacto en el relieve. La comparación entre regiones con diferente grado de aridez y de evapotranspiración permite poner a prueba la clasificación planteada por Belnap \& Lange (2003). Para ello en primer lugar evaluamos la variación microtopográfica de las CBS y en segundo lugar su influencia en la rugosidad en tres sistemas diferenciados con el grado de aridez, con el fin de comprender la influencia de las CBS en el relieve y a través de él, en las propiedades del suelo en función de variaciones climáticas.

\section{Materiales y Métodos}

La caracterización microtopográfica de las CBS y la determinación de su influencia en la rugosidad del suelo se realizó en tres sistemas diferenciados por su grado de aridez: semiárido, árido, e hiperárido mediante técnicas diferentes y complementarias.

\section{Sitios de estudio}

Sitio Semiárido: Se encuentra ubicado al suroeste de la provincia de San Juan en el Departamento de Sarmiento $\left(32^{\circ} 0^{\prime} 8,43^{\prime \prime} \mathrm{S}\right.$; $\left.68^{\circ} 45^{\prime} 10,18^{\prime \prime} \mathrm{O}\right)$ siendo la altura del área de estudio de $1139 \mathrm{msnm}$ (Fig. 1). El sitio se corresponde con el área protegida "Paisaje Protegido Pedernal" y comprende la conservación de 17.700 ha (Dalmasso et al., 2011). 


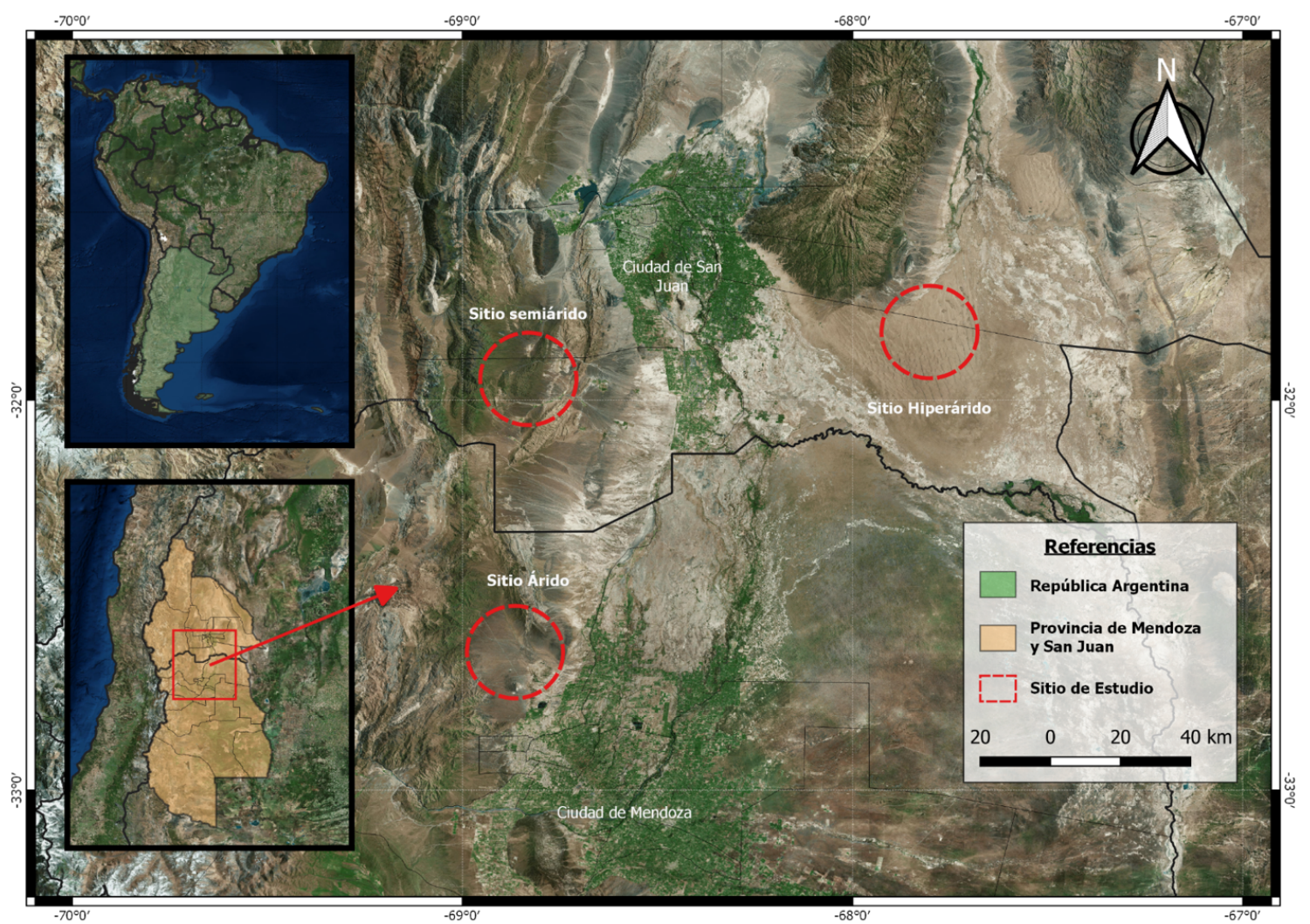

Fig. 1. Área de Estudio.

La precipitación media anual es de $370 \mathrm{~mm}$. La temperatura media anual es de $18{ }^{\circ} \mathrm{C}$, la media mínima es de $6{ }^{\circ} \mathrm{C}$ y la media máxima es de $20,7^{\circ} \mathrm{C}$ (CRAS, 1974). En esta zona los suelos corresponden al orden Entisoles y fueron clasificados en la categoría Torriortentes típicos (Regairaz, 2000; Suvires, 1987). El área de estudio pertenece a la Provincia Fitogeográfica del Monte. Dalmasso \& Márquez (2004) registraron una riqueza florística de 345 especies vasculares. Siendo características las comunidades de Zuccagnia punctata Cav., Larrea divaricata Cav., Baccharis salicifolia Ruiz y Pav. y Hyalis argéntea Don ex Hook. \& Arn.

Sitio Árido: La zona de estudio se encuentra en el departamento Las Heras (Mendoza), ámbito morfoestructural de la Precordillera de Los Andes. Se corresponde con el distrito de Capdevile. El área de estudio $\left(32^{\circ} 43^{\prime} 24,3^{\prime \prime} \mathrm{S}\right.$; $68^{\circ} 50^{\prime} 29,69^{\prime \prime}$ O) se encuentra a los $741 \mathrm{msnm}$ (Fig. 1). La precipitación anual media es de $220 \mathrm{~mm}$ y ocurre principalmente en verano (diciembre-marzo).
La temperatura media anual es de $17,5{ }^{\circ} \mathrm{C}$, la temperatura media máxima es de $30^{\circ} \mathrm{C}$ y la media mínima de $3^{\circ} \mathrm{C}$ (Norte \& Simonelli, 2010). El suelo pertenece al orden Entisoles en la categoría Torrifluventes típicos (Regairaz, 2000). Desde el enfoque fitogeográfico la vegetación pertenece a la Provincia Fitogeográfica del Monte. En el área ubicada entre los 750-1200 msnm domina un jarillal de Larrea cuneifolia (Roig, 1976; Martinez Carretero \& Dalmasso, 1992).

Sitio Hiperárido: La zona en estudio se sitúa en Los Médanos Grandes, en el departamento Caucete, en la provincia de San Juan $\left(31^{\circ} 47^{\prime} 10,13\right.$ " S, $\left.67^{\circ} 58^{\prime} 55,75^{\prime \prime} \mathrm{O}\right)$, sobre el piedemonte oriental de la Sierra Pie de Palo, a 729 msnm (Fig. 1). El bioclima de la región corresponde al Tropical Hiperárido (Pastrán et al., 2011). La temperatura media anual es de $18^{\circ} \mathrm{C}$, la temperatura máxima anual promedio es de $40^{\circ} \mathrm{C}$ y la temperatura mínima anual promedio es $10^{\circ} \mathrm{C}$ (De Fina, 1992). La precipitación media anual es de $103 \mathrm{~mm}$ y ocurre principalmente en 


\section{A. L. Navas Romero et al. - Caracterización microtopográfica de las costras biológicas del suelo}

verano (diciembre-marzo) (De Fina, 1992). En esta zona los suelos se corresponden con Entisoles en la categoría Torripsamentes típicos (Regairaz et al., 1987). Desde el enfoque fitogeográfico la vegetación pertenece a la Provincia Fitogeográfica del Monte, estando dominada por especies de la familia Zygophillaceae (Cabrera, 1971). La vegetación dominante en el área de estudio es un matorral de Bulnesia retama y Larrea divaricata, con una presencia menor de Prosopis flexuosa DC. f subinermis Burkart. en sitios deprimidos. Las especies más características son Tricomaria usillo Hook. \& Arn., Senna aphyla (Cav.) H.S. Irwin \& Borneby, L. cuneifolia, Lycium spp., Atamisquea emarginata Miers ex Hook. \& Arn., y Bougainvillea spinosa (Cav.) Heimerl.

En los tres sistemas mencionados (semiárido, árido e hiperárido) y como es común en otros desiertos de todo el mundo (Aguiar \& Sala, 1999), a escalas espaciales más pequeñas que las unidades de paisaje, la vegetación del Monte está organizada como un mosaico de dos fases compuesto por una fase de "parches" dominados por arbustos, alternando con áreas desnudas ó con escasa cobertura denominadas "interparches" (Ares et al., 2003). Comúnmente, los parches son isodiamétricos y componen la fase de la planta, lo que resulta en un patrón manchado.

\section{Diseño de muestreo}

Para la caracterización y la evaluación de la microtopografía de las CBS se emplearon en campo dos técnicas diferentes: análisis fotográfico (metodología propia) y técnica de varillas metálicas (adaptado de Amézquita et al., 1996). Ambas técnicas se emplearon de manera complementaria para caracterizar la morfología externa de las CBS dominantes en cada sistema y poner a prueba la clasificación de Belnap \& Lange (2003). Para evaluar el efecto de las CBS en la rugosidad superficial se midió la rugosidad en los tres sitios también mediante dos técnicas: el método de la cadena (adaptado de Chamizo et al., 2010) y análisis fotográfico (metodología propia). Adicionalmente en cada sistema se evaluó la textura debido a que es una propiedad que puede influir en la microtopografía.

\section{Caracterización morfológica de las CBS}

Análisis fotográfico: en cada sitio se seleccionó aleatoriamente 30 muestras de las costras biológicas dominantes: CBS dominada por líquenes y CBS dominadas por musgos para el sitio semiárido; CBS dominadas por musgos y CBS dominadas por líquenes para el sitio árido, y CBS dominada por cianobacterias y CBS dominada por musgos para el hiperárido. En cada muestra se colocó una placa metálica blanca tamaño A4 atravesando verticalmente el perfil de la costra biológica y se tomó una fotografía con cámara digital (CANON modelo T5, 18 megapíxeles) a la misma altura en todas las muestras. Cada fotografía se imprimió en tamaño real en matices grises. Sobre estas fotografías se colocó un papel milimetrado transparente y se registró la altura alcanzada por el perfil a intervalos constantes de $3 \mathrm{~mm}$ (Fig. 2A).

Varillas metálicas: Esta técnica al igual que la anterior fue aplicada sobre los tipos de CBS dominantes en cada sitio. Sobre cada tipo de CBS se colocó una placa cuadrada de poliestireno expandido de alta densidad montada con 225 varillas metálicas móviles (alfileres) de $7 \mathrm{~cm}$ de largo, dispuestas en una matriz a intervalos constantes de $5 \mathrm{~mm}$. Las varillas estuvieron colocadas verticalmente y de manera tal que su desplazamiento se realizara suavemente al tacto. Estas varillas se adaptaban a la estructura muestreada y se elevaban de acuerdo a las diferentes alturas del suelo, al apoyarlas en la superficie a medir. La técnica permitió medir 225 puntos en $225 \mathrm{~cm}^{2}$. Una vez accionadas las varillas y apoyadas en la CBS se llevó a cabo su coloración con pintura en aerosol. La lectura de las alturas de las franjas coloreadas en las varillas metálicas permitió conocer el microrrelieve de la costra biológica evaluada (Fig. 3).

\section{Influencia de las CBS en la rugosidad superficial}

Método de la cadena: este método está basado en la diferencia en longitud de una cadena colocada sobre la superficie del suelo con relieve y la colocada en una superficie plana. Para la determinación de la rugosidad a lo largo del gradiente de aridez, en cada sitio se llevó a cabo un diseño en bloques. Se trabajó en área de parche e interparche por separado, para detectar cualquier variación que podría estar enmascarada si se evaluaran juntas. Se trabajó en 60 bloques por sitio: 30 parche y 30 interparche. La situación de interparche no se consideró en el hiperárido debido a que las CBS en este sistema se limitaron al parche. En cada condición (parche e interparche) se definió un bloque, el cual estaba constituido por dos zonas: 
Bol. Soc. Argent. Bot. 54 (4) 2019

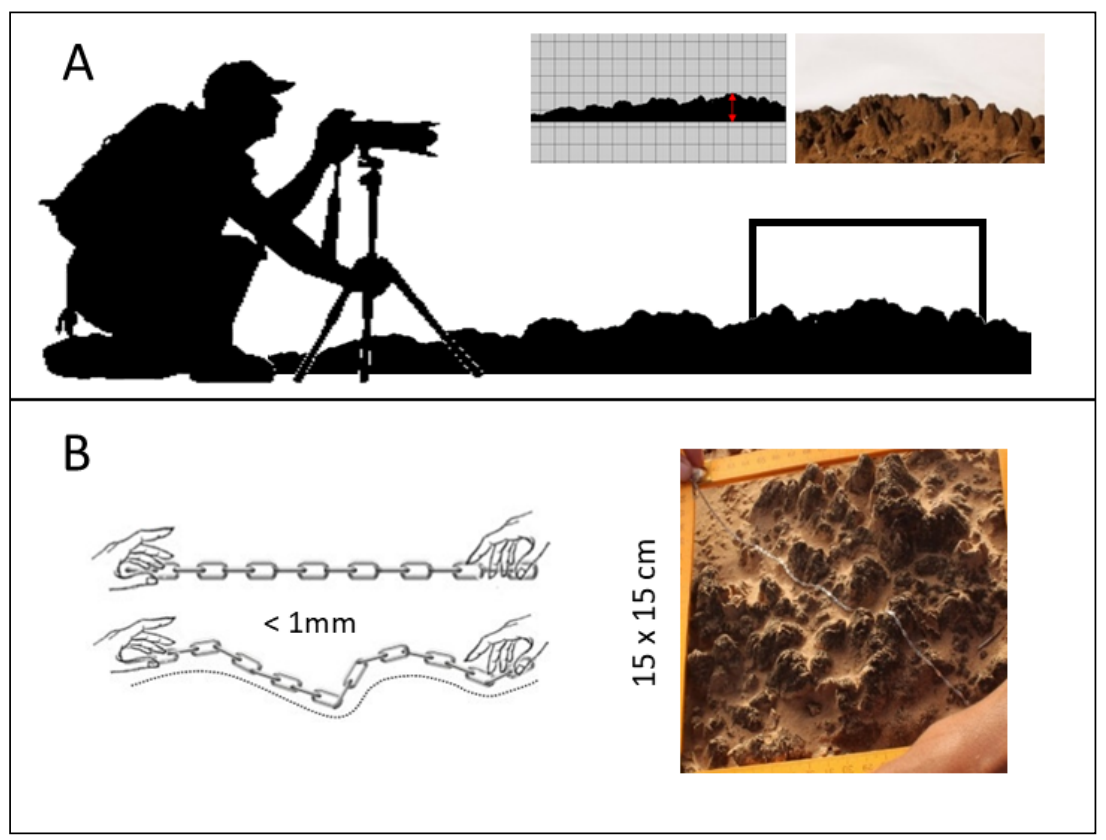

Fig. 2. A: Análisis fotográfico. Fotografía en campo del perfil de relieve de las CBS. En la parte superior se observa esquema de fotografía de CBs bajo papel milimetrado, y fotografía real de CBs en campo. B: Método de la cadena. Longitud de la cadena completamente estirada y morfología de la cadena apoyada en terreno.

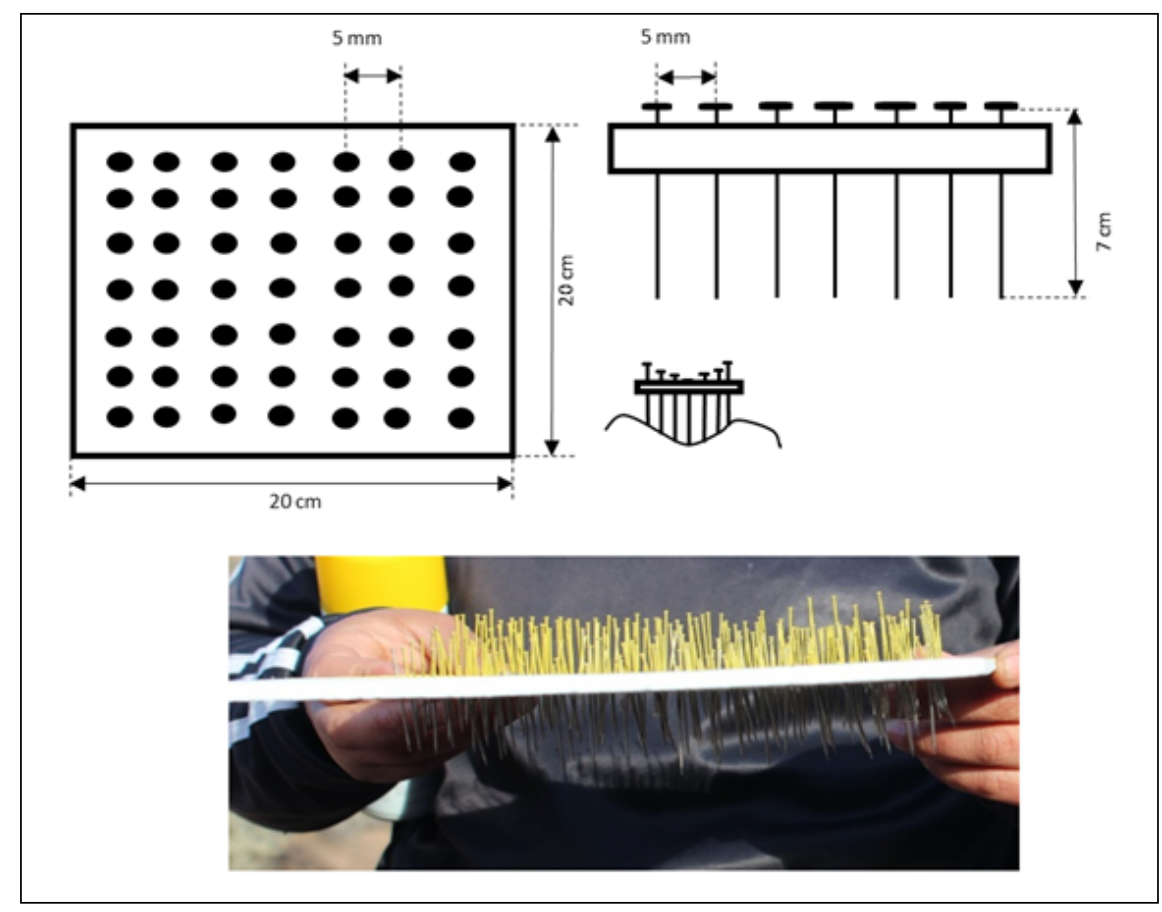

Fig. 3. Técnica de varillas metálicas. Se utilizó una placa de poliestireno expandido con perforaciones constantes, en donde se ubicaron los alfileres. 


\section{A. L. Navas Romero et al. - Caracterización microtopográfica de las costras biológicas del suelo}

una con costras biológicas (CCBS) y otra aledaña sin costras biológicas (SCBS), separadas una distancia aproximada de $10 \mathrm{~cm}$. En cada zona (CCBS y SCBS) tanto en el parche como en el interparche, se seleccionó un cuadrante de $225 \mathrm{~cm}^{2}$ $(15 \times 15 \mathrm{~cm})$, y se apoyó una cadena (de eslabón < $1 \mathrm{~mm}$ ) sobre la superficie de la CBS y se midió la longitud abarcada en dos direcciones (horizontal y oblicua) (Fig. 2B).

En los mismos bloques donde se registró la rugosidad, se evaluó la cobertura de grupos funcionales empleando dos grillas de $225 \mathrm{~cm}^{2}$. La longitud lateral de cada grilla fue de $15 \mathrm{~cm}$. La grilla contenía 36 celdas cuadráticas con una longitud lateral de 2,5 cm cada una y un ancho de las barras del marco igual a $0,5 \mathrm{~cm}$. Previo a la colocación de la grilla se removió el polvo y la hojarasca de la zona y el área fue humedecida para logra visualizar los musgos si estaban presentes. Para contabilizar la frecuencia de individuos en cada grilla se utilizó una lente de mano con un aumento de $10 \mathrm{X}$. La cobertura de musgos, líquenes y cianobacterias dentro de una parcela se registró como el número de celdas de la cuadrícula por parcela en la que el organismo fue detectado.

\section{Textura}

Para determinar la textura en cada sistema se colectaron 30 muestras de suelo en la totalidad de los bloques del parche e interparche anteriormente descriptos. La textura fue determinada por la técnica de volumen de sedimentación. Este valor fue utilizado para calcular el volumen de sedimentación (VS) de acuerdo a la ecuación:

$$
V S\left(\frac{\mathrm{ml} \%}{\mathrm{~g}}\right)=\frac{\text { Volumen del sedimento }(\mathrm{ml})}{\text { Contenido de suelo }(\mathrm{g})} * 100
$$

Con los valores del volumen de sedimentación la textura se determinó siguiendo los criterios de la Tabla 1.

\section{Análisis de datos}

Caracterización morfológica de las CBS: para la caracterización morfológica de las CBS dominantes por sitos, con los datos de alturas obtenidas en el análisis fotográfico, se construyeron perfiles promedios e histogramas de frecuencia. Con los valores de altura obtenidos para cada punto en la técnica de varillas metálicas se realizaron perfiles en tres dimensiones.
Tabla 1. Tipos de textura de suelo de acuerdo al volumen de sedimentación (VS).

\begin{tabular}{|lc|}
\hline \multicolumn{1}{|c}{ Textura del suelo } & VS $(\boldsymbol{m l} \% / g)$ \\
\hline Arenoso & $<80$ \\
Franco-arenoso & $80-93$ \\
Franco & $94-104$ \\
Franco-limoso & $105-115$ \\
Franco-arcilloso & $116-125$ \\
Franco-arcilloso-limoso & $126-139$ \\
Arcilloso & $>140$ \\
\hline
\end{tabular}

Influencia de las CBS en la rugosidad superficial: en todos los casos se aseguró la independencia estadística de los datos, la normalidad se comprobó mediante la prueba de Kolmogorov - Smirnov. La homocedasticidad mediante la prueba de Levenne. Para todos los análisis el nivel de significancia fue de $\alpha=0,05$. El índice de rugosidad (IR) se calculó como la diferencia entre la longitud de la cadena apoyada en superficie recta lisa y la obtenida en el campo. Se calculó el índice para cada dirección y luego se trabajó con la media por muestra. Para evaluar si existían diferencias en la rugosidad entre zonas CCBS vs. SCBS se comparó los valores de índice de rugosidad con un análisis de la varianza para datos agrupados, prueba de Friedmann. Para evaluar la influencia de la cobertura de los grupos componentes de la CBS en el relieve, se utilizó modelos lineales generalizados (GLM) con una distribución gaussiana, usando la función "glm" del paquete "RCMPR" (Ripley et al., 2015). El modelo completo para comprender como varió la rugosidad con los grupos funcionales dominantes en la CBS incluyó como variables independientes cobertura de musgos, cianobacterias, hepáticas, líquenes crustosos, líquenes gelatinosos, líquenes escuamulosos y las interacciones posibles entre estas variables. La estructura de los modelos se simplificó mediante la eliminación de variables e interacciones que no fueron significativamente asociadas con la variable dependiente, siguiendo el criterio de prueba de hipótesis, de acuerdo a la prueba de Wald (Bolker et al., 2009). Antes del análisis estadístico, se comprobó que los datos cumplieran con las condiciones de dispersión de los datos residuales y homogeneidad de las varianzas 
con los gráficos de diagnóstico (qqnorm en R). Para evaluar si existían diferencias en la rugosidad entre grupos de costras dominantes, se comparó los valores medios de altura obtenidos en el registro de relieve fotográfico mediante una prueba de Kruskall-Wallis y a posteriori una comparación de a pares.

Todos los análisis se realizaron utilizando el paquete estadístico "Insfostat v.18" (Di Rienzo et al., 2018) y "R studio" (R Development Core Team, 2015). Los gráficos tridimensionales fueron construidos empleando el programa SURFER para Windows 5.0 (Golden Software, Boulder, Colorado, USA). Para el resto de los gráficos se empleó el software "Sigmaplot v.11" (Systat Software, 2008).

\section{Resultados}

\section{Caracterización morfológica de las CBS \\ Sitio semiárido}

En el sitio semiárido, las costras biológicas dominadas por líquenes presentaron una morfología rodante, según Belnap \& Lange (2003), mientras que las dominadas por musgos fueron ubicadas en una categoría a la que denominamos "suavemente ondulada". Las CBS dominadas por líquenes presentaron una altura promedio de $1,79 \mathrm{~cm}$ (D.E. $=0,16$ ), con picos de cresta que alcanzaron los 5,1 $\mathrm{cm}$ y valles de $0,4 \mathrm{~cm}$ (Fig. 4A). La distribución de frecuencia de alturas para líquenes mostró una morfología sesgada hacia la derecha, con escasos representantes en algunos intervalos de clase. La mayor frecuencia de elevaciones se concentró en alturas por encima de $0,79 \mathrm{~cm}$ y debajo de los $2,75 \mathrm{~cm}$. Las alturas menos frecuentes estuvieron comprendidas entre los 3,53-4,71 cm (Fig. 5A). Las CBS dominadas por musgos presentaron una altura promedio de $1,48 \mathrm{~cm}$ (D.E. $=0,18)$, con niveles máximos de altura que alcanzaron los 3,5 $\mathrm{cm}$ y valles de 0,6 cm (Fig. 4A). La distribución de frecuencias en musgos también mostró una morfología sesgada hacia la derecha, aunque en esta ocasión la distribución entre grupos de clases fue más homogénea. La mayor frecuencia de elevaciones se concentró en alturas por encima de $0,60 \mathrm{~cm}$ y debajo de $l o s \quad 2,29 \mathrm{~cm}$. Las alturas menos frecuentes estuvieron comprendidas entre los 2,53$3,5 \mathrm{~cm}$ (Fig. 5A).
El análisis microtopográfico tridimensional permitió detectar en las CBS dominadas por líquenes una distribución heterogénea, con una disposición concéntrica de ondulaciones alrededor de profundas depresiones bien delimitadas (Fig. 6A). En las CBS dominadas por musgos, la distribución es homogénea y similar en toda su extensión, detectándose sólo leves ondulaciones y depresiones que interrumpen el terreno aparentemente liso (Fig. 6B).

\section{Sitio árido}

En el sitio árido la CBS que dominó el parche presentó una morfología de tipo lisa, dominada por musgos y de manera aislada aparecieron líquenes. Esta morfología presentó una altura promedio de $1,83 \mathrm{~cm}$ (D.E. $=0,08)$, con picos que alcanzaron $\operatorname{los} 4,9 \mathrm{~cm}$ y valles que llegaron a los $0,2 \mathrm{~cm}$ (Fig. 4B). La distribución de frecuencias de alturas para esta CBS mostró una morfología sesgada hacia la derecha (sesgo positivo). La mayor frecuencia de elevaciones se concentró en alturas por encima de $0,95 \mathrm{~cm}$ y debajo de los $2,83 \mathrm{~cm}$. Las alturas menos frecuentes estuvieron comprendidas entre los $0,2-$ $0,58 \mathrm{~cm}$ y los 3,58-4,7 cm (Fig. 5B). Por su parte, la CBS que dominó el interparche presentó una morfología de tipo rodante, dominada por líquenes, y como acompañantes aparecieron cianobacterias y musgos. Esta morfología presentó una altura promedio de $1,86 \mathrm{~cm}$ (D.E. $=0,04)$ con picos que alcanzaron los $3,8 \mathrm{~cm}$ y valles que llegaron a los $0,7 \mathrm{~cm}$ (Fig. 4B). La distribución de frecuencia de alturas para esta CBS mostró una morfología sesgada a la derecha (sesgo positivo). La mayor frecuencia de elevaciones se concentró en alturas por encima de $0,96 \mathrm{~cm}$ y debajo de $10 \mathrm{2} 2,51 \mathrm{~cm}$. Las alturas menos frecuentes estuvieron comprendidas entre los 0,2-0,58 cm y los 3,03-3,8 cm (Fig. 5B).

El análisis microtopográfico tridimensional permitió detectar en las CBS del interparche, un patrón muy similar al de las CBS del sistema semiárido. Las ondulaciones y depresiones de alturas fueron de dimensiones similares en toda el área evaluada, aunque de mayor tamaño que las observadas para el sistema semiárido. En las CBS del parche dominadas por líquenes se visualizó una distribución similar a la de líquenes para el semiárido, pero con ondulaciones y depresiones escasamente marcadas, que impidieron detectar la distribución concéntrica de las ondulaciones. 


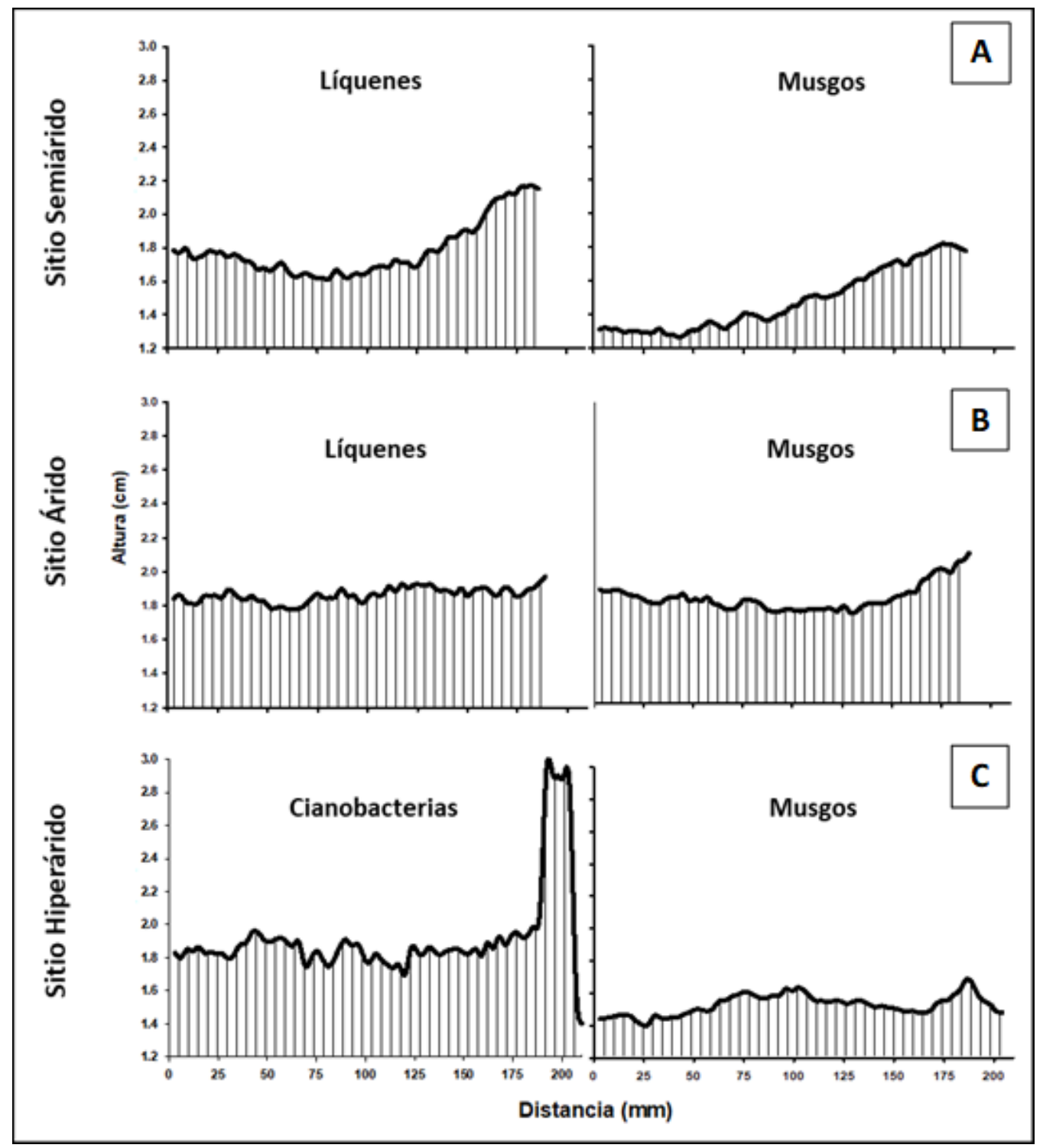

Fig. 4. Curvas de perfiles en dos dimensiones que muestra las alturas promedio para cada una de las costras biológicas dominantes en los sitios. A: semiárido, B: árido, C: hiperárido.

En este caso sólo se detectó una distribución aleatoria de depresiones que interrumpieron la monotonía lisa del paisaje (Fig. 7A). En las CBS del parche dominadas por musgos, la distribución fue menos homogénea que en el sistema semiárido, aunque similar en toda su extensión, detectándose sólo escasas ondulaciones y depresiones que interrumpieron un terreno relativamente llano (Fig. 7B).

\section{Sitio hiperárido}

En el sitio hiperárido, las CBS dominadas por cianobacterias presentaron una morfología de tipo pinaculada, según Belnap \& Lange (2003); la altura media fue de $1,92 \mathrm{~cm}$ (D.E. $=0,29)$ con picos que alcanzaron los $5,6 \mathrm{~cm}$ y valles que llegaron a los $0,2 \mathrm{~cm}$ (Fig. 4C). La distribución de frecuencia de alturas para cianobacterias mostró un desplazamiento hacia la 


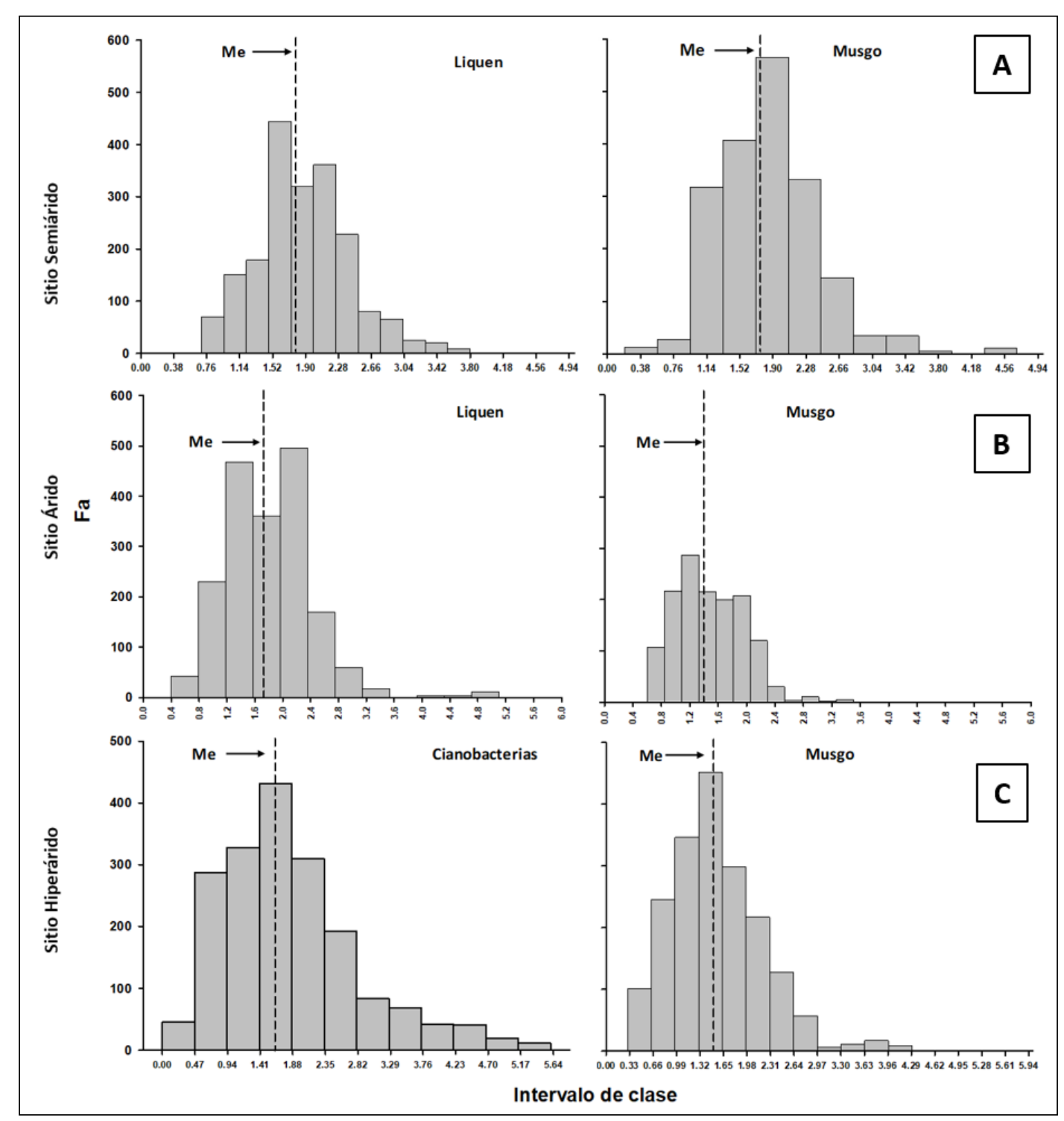

Fig. 5. Histograma de frecuencias absolutas (Fa) de altura para cada uno de los grupos de CBS dominantes en los sitios. A: semiárido, B: árido, C: hiperárido. Se muestra la mediana (Me). Intervalos de clase en cm.

izquierda (sesgo negativo). La mayor frecuencia de elevaciones se concentró en alturas por encima de $0,47 \mathrm{~cm}$ y debajo de $\operatorname{los} 2,80 \mathrm{~cm}$. Las alturas menos frecuentes estuvieron comprendidas entre los 5,13-5,60 cm (Fig. 5C). Las CBS dominadas por musgos presentaron una morfología tipo "suavemente ondulada", siendo la altura media de $1,53 \mathrm{~cm}($ D.E. $=1,43)$ con picos que alcanzaron los $4,3 \mathrm{~cm}$ y valles que llegaron a $\operatorname{los} 0,3 \mathrm{~cm}$
(Fig. 4C). La distribución de frecuencias de alturas para musgos fue aún más marcada que para cianobacterias, con un claro desplazamiento hacia la izquierda, y muy pocos representantes en algunos intervalos de clase. La mayor frecuencia de elevaciones se concentró en alturas por encima de $0,63 \mathrm{~cm}$ y debajo de $\operatorname{los} 2,30 \mathrm{~cm}$. Las alturas menos frecuentes estuvieron comprendidas entre los 3,30-3,63 cm (Fig. 5C). 


\section{A. L. Navas Romero et al. - Caracterización microtopográfica de las costras biológicas del suelo}

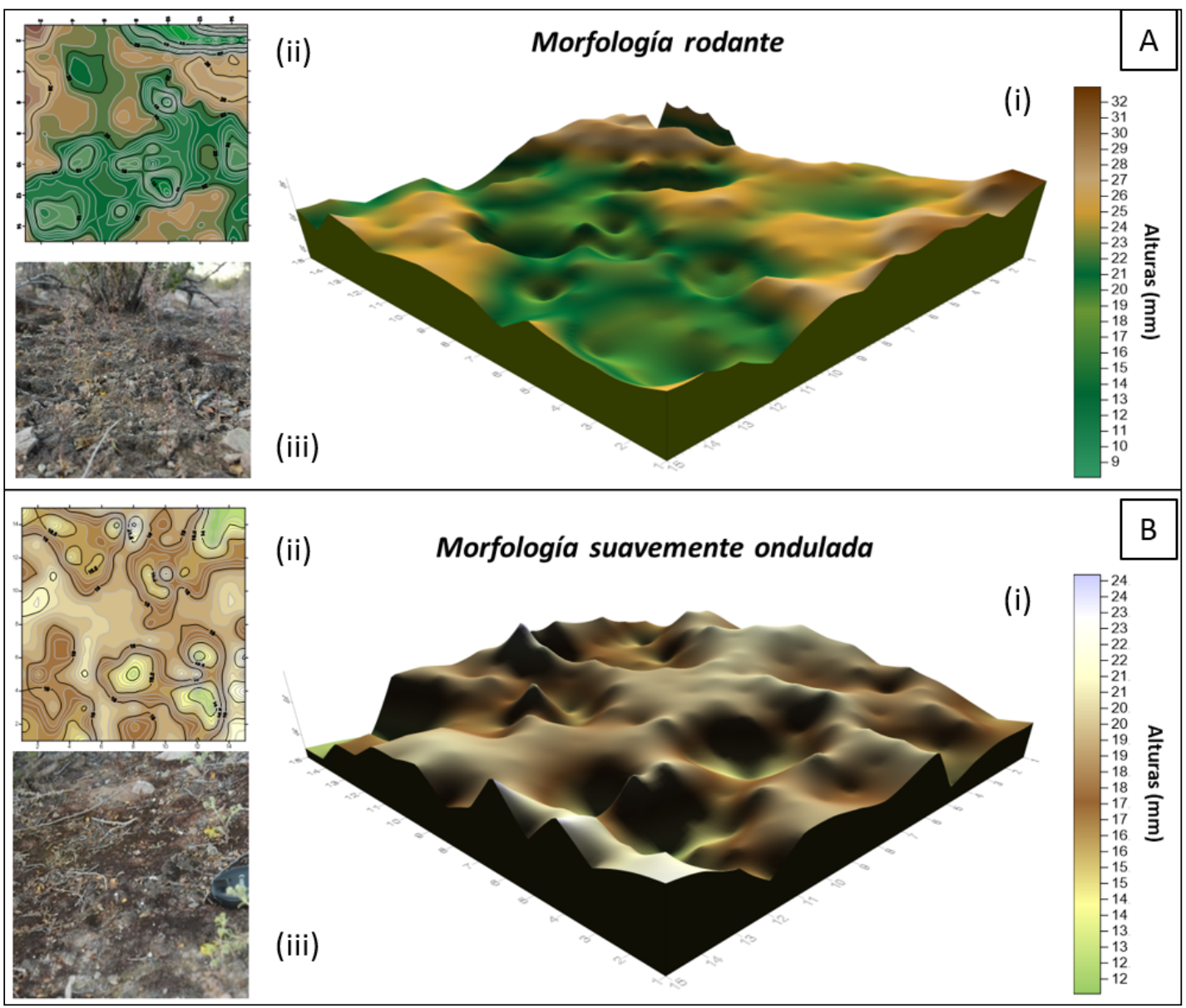

Fig. 6. A: líquenes y B: musgos. i: Morfología externa en tres dimensiones de la costra biológica dominantes en el sistema semiárido. ii: fotografía de la zona relevada, iii: mapa de contorno (cotas más comprimidas indican mayor profundidad en el terreno).

En este sistema dos grupos de CBS fueron los dominantes: CBS dominada por musgos y CBS dominada por cianobacterias. El análisis microtopográfico tridimensional permitió detectar en las CBS dominadas por musgos un patrón muy similar a los otros dos sistemas, con un patrón mayoritariamente plano y ocasionales elevaciones y depresiones muy suaves que aparecieron de manera aleatoria (Fig. 8A). Las CBS dominadas por cianobacterias, presentaron un patrón homogéneo con marcadas elevaciones y profundas depresiones en el terreno, generando un relieve con caídas muy abruptas (Fig. 8B).

\section{Influencia de las CBS en la rugosidad superficial}

El sitio semiárido fue el que mostró una menor variación en la rugosidad entre zonas. En la condición del parche el relieve fue superior en la zona CCBS $(\mathrm{CCBS}=4,40 \pm 1,73 \mathrm{~cm} ; \mathrm{SCBS}=3,77 \pm 1,47 \mathrm{~cm})$, encontrándose diferencias significativas entre la zona con CCBS y la SCBS ( $\mathrm{T}=6,19 ; \mathrm{p}<0,0143$ ). En el interparche la zona SCBS tendió a presentar mayor rugosidad $(\mathrm{CCBS}=4,10 \pm 1,68 \mathrm{~cm}$; SCBS $=4,32 \pm 1,89 \mathrm{~cm}$ ), sin embargo, no se encontraron diferencias significativas. Al comparar el índice de rugosidad en las zonas CCBS entre condiciones (parche-interparche) este tendió a ser superior en el parche $(4,40 \pm 1,73)$, sin embargo, no se encontraron diferencias significativas entre condiciones.

El sitio árido presentó valores intermedios entre los otros dos sistemas. En este sistema, a diferencia 


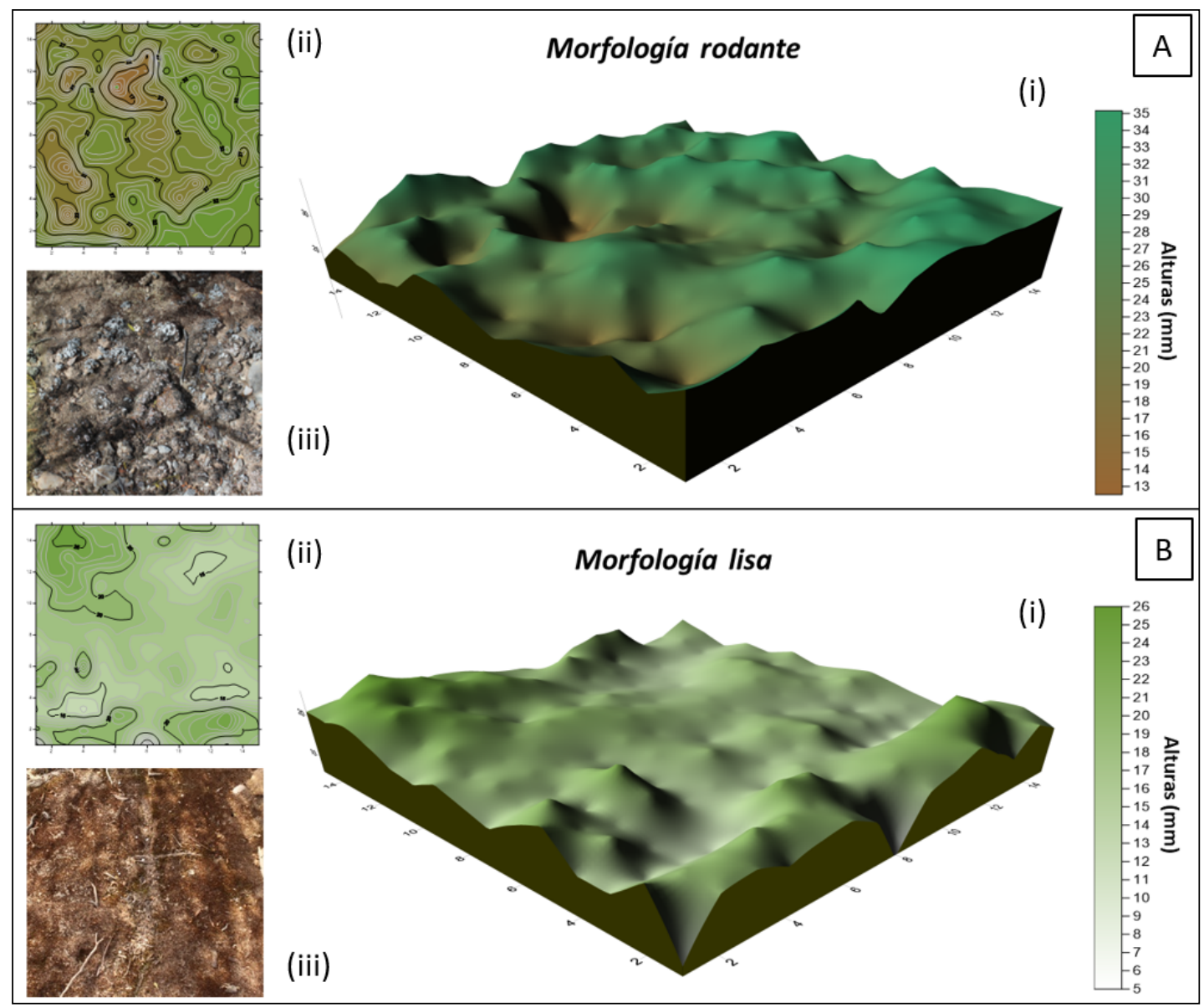

Fig. 7. A: líquenes y B: musgos. i: Morfología externa en tres dimensiones de la costra biológica dominantes en el sistema árido. ii: fotografía de la zona relevada, iii: mapa de contorno (cotas más comprimidas indican mayor profundidad en el terreno).

del semiárido, los valores del índice de rugosidad siempre fueron superiores en la zona CCBS (parche $\mathrm{CCBS}=3,73 \pm 1,31 \mathrm{~cm} ; \mathrm{SCBS}=2,99 \pm 1,23 \mathrm{~cm}$; interparche $\mathrm{CCBS}=4,05 \pm 1,14 \mathrm{~cm} ; \mathrm{SCBS}=3,21 \pm$ $1,13 \mathrm{~cm})$. Las diferencias en el relieve entre la zona CCBS y la SCBS fueron significativas en el parche $(\mathrm{T}=17,70 ; \mathrm{p}<0,0001)$ e interparche $(\mathrm{T}=33,93$; $\mathrm{p}<0,0001)$. Al comparar el índice de rugosidad en las zonas CCBS entre condiciones (parche-interparche), este tendió a ser superior en el interparche $(4,05 \pm$ $1,14)$, sin embargo, no se encontraron diferencias significativas entre condiciones.

Las CBS del sitio hiperárido fueron las que mostraron mayor influencia en la rugosidad superficial, llegando en este sistema las zonas CCBS
$(3,72 \pm 2 \mathrm{~cm})$ a duplicar la rugosidad con respecto a las SCBS $(2 \pm 1,64 \mathrm{~cm})$, encontrándose diferencias significativas entre zonas $(\mathrm{T}=77,34 ; \mathrm{p}<0,0001)$.

En cuanto a la influencia de la cobertura de grupos dominantes en la rugosidad superficial, en el sistema semiárido para el parche el modelo que más se ajustó fue el que involucró hepáticas y líquenes gelatinosos explicando este modelo el $17,4 \%$ de la variabilidad, no así en el interparche donde el modelo sólo explicó el 7,5\% de la variabilidad de los datos e involucró a cianobacterias y líquenes escuamulosos. En el sistema árido el modelo que más se ajustó en la zona de parche fue el que involucró sólo la suma de hepáticas, líquenes crustosos, gelatinosos y escuamulosos explicando 


\section{A. L. Navas Romero et al. - Caracterización microtopográfica de las costras biológicas del suelo}

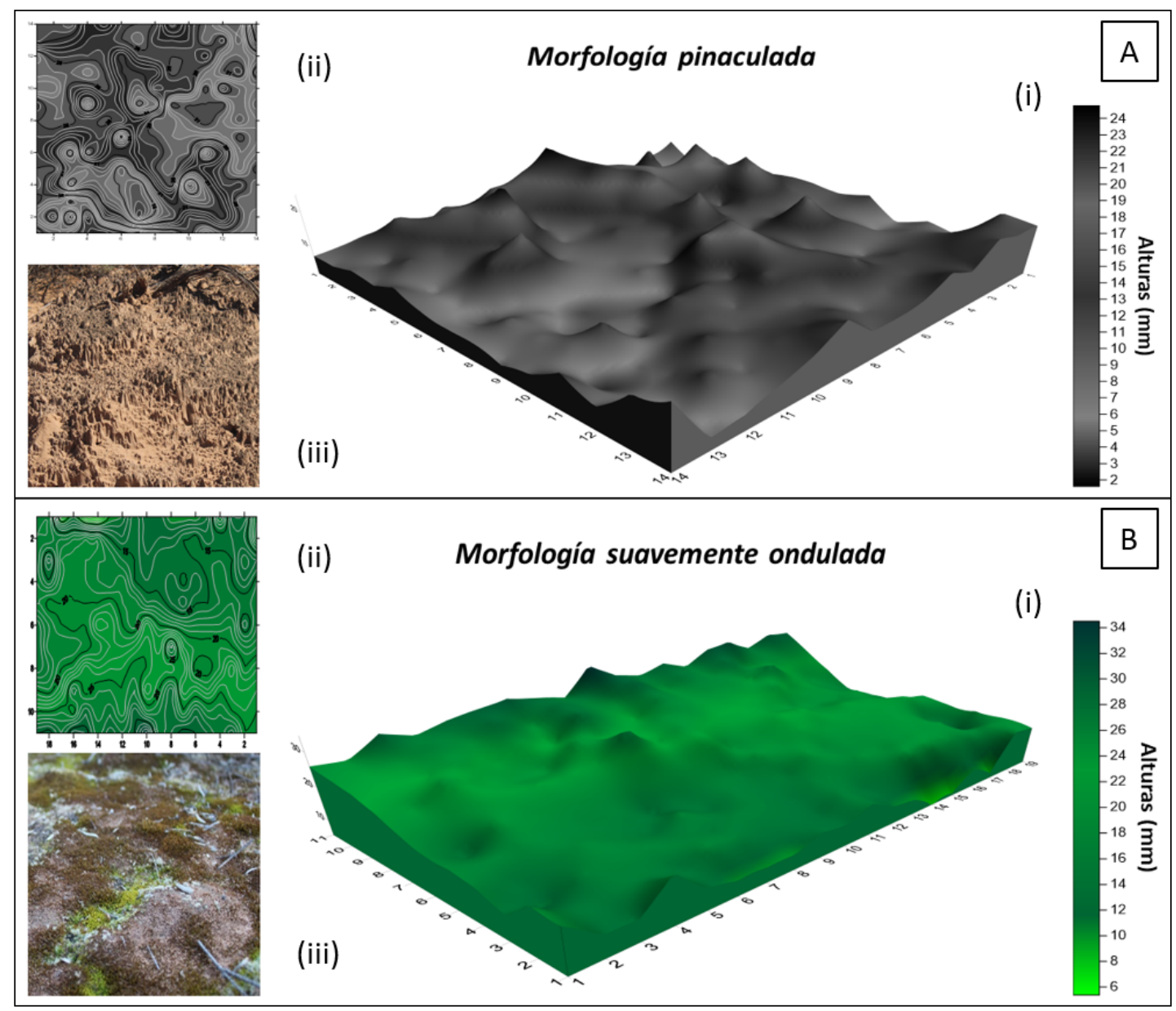

Fig. 8. A: musgos y B: cianobacterias. i: Morfología externa en tres dimensiones de la costra biológica dominantes en el sistema hiperárido. ii: fotografía de la zona relevada, iii: mapa de contorno (cotas más comprimidas indican mayor profundidad en el terreno).

el $25,8 \%$ de la variabilidad total de los datos, y en el interparche el modelo que involucró líquenes crustosos y líquenes gelatinosos, aunque en este caso sólo explicó el 12,2\% de la variabilidad de los datos. En el sistema hiperárido, el modelo que más se ajustó fue el que involucró la interacción cianobacterias, líquenes escuamulosos y líquenes gelatinosos. Aunque sólo explicó el 14,5 \% de la variabilidad de los datos (Tabla 2).

En cuanto a las diferencias en el relieve según el grupo que dominó en la CBS, en el sistema semiárido el relieve proporcionado por líquenes $(1,79 \pm 0,48 \mathrm{~cm})$ fue mayor que el proporcionado por musgos $(1,50 \pm 0,44 \mathrm{~cm})$, encontrándose diferencias significativas $(H=4,68 ; p<0,0305)$.
En el árido, si bien el relieve mostró una tendencia a ser mayor en las CBS del interparche $(1,86 \pm$ $0,42 \mathrm{~cm})$ con respecto a las que dominaron en el parche $(1,83 \pm 0,46 \mathrm{~cm})$, no se encontraron diferencias significativas. El sistema hiperárido mostró diferencias significativas entre el relieve proporcionado por musgos y por cianobacterias $(\mathrm{H}=5,12 ; \mathrm{p}<0,0237)$, siendo mayor el relieve proporcionado por cianobacterias $(1,86 \pm 0,60 \mathrm{~cm})$ que el por musgos $(1,53 \pm 0,47 \mathrm{~cm})$.

\section{Textura}

El sistema semiárido presento un volumen de sedimentación promedio de 108,5 ( $\pm 6,5$, ubicándose en la categoría "franco-limoso", el árido un 
Tabla 2. Detalle de los modelos para la rugosidad en función de la cobertura de los grupos componentes de las CBS para los tres sistemas analizados Semiárido- Árido- Hiperárido. Abreviaturas= C: Cianobacterias, D2: devianza residual, E.E.: error estandar, H: Hepáticas, LC: Liquen crustoso, LE: Liquen escuamuloso, LG: Liquen gelatinoso, M: Musgos.

\begin{tabular}{|lccccccc|}
\hline Sistema & Condición & Modelo & Estimador & E.E. & Devianza & D2 & Valor $\mathbf{p}$ \\
\hline \multirow{2}{*}{ Semiárido } & Parche & H+LG+M & 6,15 & 0,39 & 17,4 & 294,85 & $0,0001\left(^{*}\right)$ \\
& Interparche & C+LE & 3,19 & 0,36 & 7,55 & 286,72 & $0,0001\left(^{*}\right)$ \\
\hline \multirow{2}{*}{ Árido } & Parche & H+LC+LE+LG & 3,32 & 0,24 & 25,8 & 151,43 & $0,0001\left(^{*}\right)$ \\
& Interparche & LC+LG & 3,79 & 0,15 & 12,2 & 133,63 & $0,0001\left(^{*}\right)$ \\
\hline Hiperárido & Parche & LG:LE:C & $-0,82$ & 0,27 & 14,5 & 405,83 & $0,0038\left(^{*}\right)$ \\
\hline
\end{tabular}

promedio de 107,4 ( \pm 5.8, ubicándose en la misma categoría, mientras que el hiperárido presentó un volumen de sedimentación de 70,3 ( $\pm 6,3$ ubicándose en la categoría "arenoso".

\section{Discusión}

\section{Caracterización morfológica de las CBS}

Los perfiles topográficos de las CBS evaluadas mostraron una gran variación interna, dada principalmente por los grupos que dominaron en cada sitio. Sin embargo, dentro de esta variación interna se logró detectar un patrón para cada grupo de CBS. Con alturas más suavizadas y menos pronunciadas para musgos, picos más abruptos para CBS dominadas por cianobacterias y dos frecuencias de alturas para CBS dominadas por líquenes.

En los tres sitios estudiados, las morfologías se correspondieron sólo en parte con el gradiente ETP según Belnap \& Lange (2003), aunque las morfologías de CBS dominantes en cada sitio se pudieron ajustar a las formas típicas.

Las CBS dominadas por cianobacterias se ubicaron dentro de la categoría pinaculadas correspondiéndose sólo en parte con la clasificación propuesta por Belnap \& Lange (2003), hallándose en el sitio hiperárido que mostró la ETP más alta. La textura del suelo y la erosión del viento podrían ser los principales factores que modelarían la morfología en este sistema. Belnap (2006), mencionó que estos montículos con forma de castillo, pueden llegar a alcanzar $15 \mathrm{~cm}$ de altura y que la colonización en las puntas por líquenes y musgos, sería lo que les otorgaría estabilidad a los pináculos. La morfología pinaculada ha sido descripta para CBS que habitan en sistemas con clima tropical, subtropical, mediterráneo, continental seco, pero también en zonas climáticas ártico-alpinas (Colesie et al., 2016). Belnap (2006) mencionó que estas costras eran comunes en los desiertos fríos como la meseta de Colorado y la latitud media de China. Además, se refirió a ellas como las más sensibles a las perturbaciones, ya que la gran superficie elevada se rompe fácilmente, enterrando a menudo los microrganismos que la habitan.

Las CBS dominadas por líquenes y cianobacterias, se ubicaron dentro de la categoría rugosas y estuvieron presentes en el interparche del semiárido y del árido. En este caso en particular se ajustaron a la clasificación de Belnap \& Lange (2003), ubicándose entre los sitios semiárido y árido con menor ETP. A diferencia de las cianobacterias, los líquenes tienen casi todo su tejido fotosintético sobre la superficie del suelo. Los talos sobre la superficie del suelo son los que les otorgan la rugosidad a las CBS. Así, la morfología de los organismos al controlar la cantidad de polvo depositada, van definiendo la topografía superficial (Colesie et al., 2016). A diferencia de las cianobacterias, estos organismos taloides agregan un componente de crecimiento vertical a la CBS permitiendo su expansión tridimensional. Belnap \& Lange (2003), mencionaron que este tipo de CBS son comunes en regiones frías como las de la gran cuenca del Norte de EE.UU., las estepas del norte de Mongolia y el ártico. Lan et al. (2012) describieron, una morfología de costras rugosas 


\section{A. L. Navas Romero et al. - Caracterización microtopográfica de las costras biológicas del suelo}

para líquenes con una capa de talo de hasta de 1 $\mathrm{mm}$ por encima de la superficie del suelo. Por su parte Colesie et al. (2014) describieron a las CBS dominadas por líquenes crustosos en la Antártida como aquellas con un espesor de 4,5 $\mathrm{mm}$.

Finalmente, las CBS dominadas por musgos, presentes en el hiperárido y el semiárido, no se ubicaron en ninguna de las categorías propuestas. $\mathrm{Su}$ morfología, que posee un patrón propio, representó un intermedio entre los otros grupos, conformando una nueva categoría, a la que denominamos "suavemente ondulada". Al igual que en los líquenes, los musgos tienen todo su tejido fotosintético sobre la superficie, siendo éste el que define en primera instancia su microtopografía externa (Colesie et al., 2016). Costras biológicas dominadas por musgos ya habían sido descriptas por Lan et al. (2012); sin embargo, ellos se refirieron a éstas como una capa de tallo-hoja que se encuentra $2 \mathrm{~mm}$ por encima de la superficie del suelo, sin hacer referencia a su morfología.

\section{Influencia de las CBS en la rugosidad superficial}

En los tres sitios estudiados: semiárido, árido e hiperárido, la presencia de las CBS en la capa superficial del suelo alteró la fisonomía, influyendo en la rugosidad superficial, siendo el sitio hiperárido en el que se produjo mayor impacto en la rugosidad. El incremento en la rugosidad como consecuencia de la presencia de CBS, ha sido reportado en algunos trabajos (Kidron, 2007; Chamizo et al., 2010). Chamizo et al. (2010), encontraron mayores niveles de rugosidad en CBS dominadas por líquenes y cianobacterias en ecosistemas áridos mediterráneos de España. Asimismo, Rodríguez-Caballero et al. (2012, 2015), hallaron un incremento en la rugosidad en suelos cubiertos por CBS dominadas por cianobacterias en comparación con el suelo desnudo.

Las variaciones encontradas en la rugosidad entre los sitios estudiados no se correspondieron con las reportadas para esas condiciones climáticas. Las CBS del sitio hiperárido, contrario a lo que se sustenta, fueron las que generaron una mayor contribución al microrrelieve. En este sitio, la textura del suelo, junto con la dinámica erosiva del sistema, jugaría un rol clave. Así, las bajas precipitaciones, elevadas temperaturas sumado a los fuertes vientos y abundante escorrentía (Pastrán et al., 2011), modelarían el paisaje conduciendo a la formación de pináculos. Por su parte, en el sitio semiárido y en el árido, la pedregosidad del terreno, la textura franco-limosa, el cambio en los grupos dominantes de la CBS y la disminución de los vientos, impedirían el fuerte modelado generando relieves ondulados y menos abruptos. La presencia de rocas le otorga rugosidad al terreno haciendo que las diferencias en rugosidad entre zonas CCB y SCB sean menos notables. La textura franco-limosa en relación a la arenosa, es más densa y más dura para ser modelada, en la arenosa pequeños pulsos de precipitaciones producen grandes surcos en el terreno generando relieves más abruptos, mientras que en la arcillosa se requieren grandes pulsos de precipitación o periodos continuos de la misma para generar el mismo efecto. Por otra parte, en estos sistemas los grupos de CBS que dominaron fueron líquenes y musgos, estas comunidades a diferencias de las CBS dominadas por cianobacterias se encuentran estructuralmente más integradas y adheridas con las partículas del suelo, formando morfologías más firmes y compactas y, por lo tanto, presentando una mayor resistencia a los procesos erosivos (viento, agua) siendo escaso su modelado. Además, en estos sistemas los períodos con al menos una hora de calma son de 110 días para el semiárido, 88 días para el árido, con una velocidad promedio para el resto de los días de $2,9 \mathrm{~m} / \mathrm{s}$ y $3,1 \mathrm{~m} / \mathrm{s}$ para el semiárido y árido respectivamente, mientras que en el hiperárido los días con calma son sólo 44 días, teniendo el viento una velocidad promedio de $4 \mathrm{~m} / \mathrm{s}$ (Servicio Meteorológico Nacional, Estación Chacras de Coria, Aeropuerto Mendoza, Aeropuerto San Juan). Estos mayores vientos en el hiperárido sumado a su textura arenosa permite moldear más fácilmente las superficies colonizadas por CBS en este sistema y más difícilmente en el árido y semiárido.

La relación entre la cobertura del grupo funcional dominante (musgo, cianobacteria, liquen gelatinoso, crustoso, escuamuloso) y la rugosidad, no mostró un patrón claro, indicando que, al menos en los sitios evaluados, la relación parece ser más compleja. No obstante, sí encontramos diferencias entre el incremento en la rugosidad y el tipo de CBS dominante, al menos en dos de los sitios estudiados (hiperárido y semiárido). La mayor complejidad microtopográfica asociada con el incremento en 
el desarrollo de las CBS ha sido reportado en numerosos trabajos (Kidron et al., 2003; Kidron, 2007; Kidron et al., 2010; Chamizo et al., 2010; Rodríguez-Caballero et al., 2012). Asimismo, Wang et al. (2014), empleando la misma técnica, encontraron variaciones en la rugosidad del suelo en función de la etapa sucesional de la CBS con una disminución del $47 \%$ en la etapa de sucesión inicial (CBS dominadas por cianobacterias claras) y un incremento del $20 \%$ con el desarrollo de las CBS (CBS dominadas por cianobacterias oscuras). De igual manera, Wang et al. (2017) y Rodriguez-Caballero et al. (2015) encontraron diferencias en la rugosidad proporcionada por CBS dominadas por musgos, cianobacterias y líquenes; dicho incremento en la rugosidad no sólo estuvo determinado por su morfología en seco, sino que la humectación de las comunidades produjo un incremento adicional en la microtopografía proporcionada a la superficie del suelo.

\section{Conclusiones}

El microrrelieve de las CBS varió según el tipo de organismo dominante. Los musgos tuvieron una baja altura clasificándose como "suavemente ondulados", las cianobacterias tuvieron picos más abruptos, clasificándose como pinaculadas y los líquenes tuvieron dos frecuencias de alturas clasificándose como rodantes. A escala regional, el régimen general de temperatura y lluvias puede tener una influencia formativa en la estructura de la CBS, principalmente controlando la composición específica. Sin embargo, a escala local, la textura y química del suelo, y los procesos erosivos dominantes, podrían modificar la morfología externa de las CBS del suelo en un sistema, generando variedades únicas. Así, a pesar de las tendencias generales en la estructura de la CBS, su morfología general debe ser evaluada en cada sistema en particular.

Las CBS influyeron en la rugosidad del suelo en los tres sitios evaluados. El sitio hiperárido fue el sitio en el que mayor impacto tuvieron las CBS en la rugosidad. El tipo de CBS dominante influyó en el nivel de rugosidad hallado. Por lo tanto, aceptamos la hipótesis de que las CBS modifican la rugosidad del suelo y que esta modificación varía con el gradiente de aridez.

\section{Contribución de los Autores}

ALNR, MAHM y EMC diseñaron, realizaron la investigación y colectaron el material de campo. MAD y MCFB colaboraron con los análisis estadísticos y la interpretación. Todos los autores participaron en la escritura del manuscrito.

\section{Agradecimientos}

Agradecemos a Heber Merenda, David Ponce, José Vasquez y Yamil Rodriguez por su colaboración durante los muestreos. Este trabajo fue parcialmente financiado por una beca doctoral-CONICET y un proyecto HOLCIM-Fundación CRICYT.

\section{Bibliografía}

AGUIAR, M. \& O. SALA. 1994. Competition, facilitation, seed distribution and the origin of patches in a Patagonian steppe. Oikos 70: 26-34. https://doi.org/10.2307/3545695

AMÉZQUITA, E., L. CHAVÉZ \& A. ALVAREZ. 1996. Diseño, construcción y uso de un microrelievímetro para evaluar la dinámica de la erosión en áreas de ladera. Techn. Bull. Centro Int. Agric. Trop. 9 pp.

ANTOINE, M., M. JAVAUX \& C. BIELDERS. 2009. What indicators can capture runoff-relevant connectivity properties of the micro-topography at the plot scale? Adv. Water Resour. 32: 1297-1310. https://doi.org/10.1016/j.advwatres.2009.05.006.

ARES, J., H. DEL VALLE \& A. BISIGATO. 2003. Detection of process-related changes in plant patterns at extended spatial scales during early dryland desertification. Glob. Change Biol. 9: 1643-1659. https://doi.org/10.1046/j.1365-2486.2003.00690.x

BATES, S. \& F. GARCIA-PICHEL. 2009. A CultureIndependent study of free-living fungi in biological soil crusts of the Colorado Plateau: Their diversity and relative contribution to microbial biomass. Environ. microbiol. 11: 56-67. https://doi.org/10.1111/j.1462-2920.2008.01738.x

BELNAP, J. 2006. The potential roles of biological soil crusts in dryland hydrologic cycles. Hydrol. Process. 20: 3159-3178. https://doi.org/10.1002/hyp.6325.

BELNAP, J. \& O. L. LANGE. 2001. Structure and functioning of biological soil crusts: a synthesis. In: BELNAP, J. \& O. L. LANGE (eds.), Biological Soil 


\section{A. L. Navas Romero et al. - Caracterización microtopográfica de las costras biológicas del suelo}

Crusts: Structure, Function, and Management, pp. 471-479. Springer, Berlin, Heidelberg.

BELNAP, J. \& O. LANGE. 2003. Biological soil crust structure and function. Springer, Berlin. https://doi.org/10.1007/978-3-642-56475-8_20

BELNAP, J., J. WELTER, N. GRIMM, N. BARGER \& J. LUDWIG. 2005. Linkages between microbial and hydrologic processes in arid and semiarid watersheds. Ecology 86: 298-307.

https://doi.org/10.1890/03-0567.

BERALDI-CAMPESI, H., HARTNETT, H., ANBAR, A., GORDON, G. \& F. GARCIA-PICHEL. 2009. Effect of biological soil crusts on soil elemental concentrations: implications for biogeochemistry and as traceable biosignatures of ancient life on land. Geobiology 7: 348-359.

https://doi.org/10.1111/j.1472-4669.2009.00204.x

BOLKER, B., M. BROOKS, C. CLARK, S. GEANGE, J. POULSEN, M. STEVENS \& J. WHIT. 2009. Generalized linear mixed models: a practical guide for ecology and evolution. Trends Ecol. Evol. 24: 127-135. https://doi.org/10.1016/j.tree.2008.10.008

BOWKER, M., J. BELNAP, D. DAVIDSON \& S. PHILLIPS. 2005. Evidence for micronutrient limitation of biological soil crusts: importance to arid-lands restoration. Ecol. Appl. 15: 1941-1951. https://doi.org/10.1890/04-1959

CABRERA, A. 1971. Fitogeografía de la República Argentina. Bol. Soc. Argen. Bot. 14: 1-50.

CHAMIZO, S., E. RODRÍGUEZ-CABALLERO, I. MiRAlLES-MELLADO, A. AFANA, R. LÁZARO, F. DOMINGO, A. CALVO-CASES, A. SOLE-BENET \& Y. CANTÓN. 2010. Características de las costras físicas y biológicas del suelo con mayor influencia sobre la infiltración y la erosión en ecosistemas semiáridos. Pirineos 165: 69-96.

https://doi.org/10.3989/Pirineos.2010.165004

CHAMIZO, S., Y. CANTÓN, E. RODRÍGUEZCABALLERO, F. DOMINGO \& A. ESCUDERO. 2012. Runoff at contrasting scales in a semiarid ecosystem: a complex balance between biological soil crust features and rainfall characteristics. $J$. Hydrol. 452-453: 130-138.

https://doi.org/10.1016/j.jhydrol.2012.05.045

COLESIE, C., T. ALLAN GREEN, I. HAFERKAMP \& B. BÜDEL. 2014. Habitat stress initiates changes in composition, $\mathrm{co}_{2}$ gas exchange and c-allocation as life traits in biological soil crusts. ISME J. 8: 2104-2115. https://doi.org/10.1038/ismej.2014.47
COLESIE, C., V. FELDE \& B. BÜDEL. 2016. Composition and macrostructure of biological soil crusts. In: WEBER B., B. BÜDEL, \& J. BELNAP (eds.), Biological Soil Crusts: An Organizing Principle in Drylands, pp. 159-172. Springer, Cham. https://doi.org/10.1007/978-3-319-30214-0_9

CRAS. 1974. Informe sobre hidrogeologia de Pedernal N 804. San Juan, Argentina.

DALMASSO, A. \& J. MARQUEZ. 2004. Vegetación de la Pampa del Acequión y alrededores (San Juan). Multequina 13: 15-31.

DALMASSO, A., J. MÁRQUEZ, A. ABARCA, R. MONTECCHIANI, M. ROSALES, \& E. ZABALETA. 2011. Flórula del paraje de Pedernal y alrededores: departamento Sarmiento, San Juan. INCA, San Juan, 1-84.

DARBOUX, F., P. DAVY \& C. GASCUEL-ODOUX. 2002. Effect of depression storage capacity on overland-flow generation for rough horizontal surfaces: water transfer distance and scaling. Earth Surf. Proc. Land. 27: 177-191. https://doi.org/10.1002/esp.312.

DE FINA, A. 1992. Aptitud agroclimática de la República Argentina. 402 pp. Buenos Aires.

DI RIENZO, J., M. BALZARINI, L. GONZALEZ, F. CASANOVES, M. TABLADA \& C.W. ROBLEDO. 2010. InfoStat/L software estadístico versión 2018. Universidad Nacional de Córdoba (FCA-UNC).

EVANS, R. \& J. JOHANSEN.1999. Microbiotic crusts and ecosystem processes. Cr. Rev. Plant. Sci. 18: 183225. https://doi.org/10.1080/07352689991309199

GARCIA-PICHEL, F., S. JOHNSON, D. YOUNGKIN \& J. BELNAP. 2003. Small-Scale Vertical distribution of bacterial biomass and diversity in biological soil crusts from arid lands in the Colorado Plateau. Microb. Ecol. 46: 312-321. https://doi.org/10.1007/s00248-003-1004-0

GOVERS, G., I. TAKKEN, \& K. HELMING. 2000. Soil roughness and overland flow. Agronomie 20: 131-146. https://doi.org/10.1051/agro:2000114

ISSA, O., J. TRICHET, C. DÉFARGE, A. COUTÉ \& C. VALENTIN. 1999. Morphology and Microstructure of microbiotic soil crusts on a tiger bush sequence (Niger, Sahel). Catena 37: 175-196. https://doi.org/10.1016/S0341-8162(99)00052-1.

JOHNSON, S., S. NEUER \& F. GARCIA PICHEL. 2007. Export of nitrogenous compounds due to incomplete cycling within biological soil crusts of arid lands. Environ. Microbiol. 9: 680-689. https://doi.org/10.1111/j.1462-2920.2006.01187.x 
JONES, C., J. LAWTON \& M. SHACHAK. 1997. Positive and negative effects of organisms as physical ecosystem engineers. Ecology 78:1946-1957. https://doi.org/10.1890/00129658(1997)078[1946:PANEOO]2.0.CO;2

KIDRON, G. 2007. Millimeter-scale microrelief affecting runoff yield over microbiotic crust in the Negev Desert. Catena 70: 266-273. https://doi.org/10.1016/j.catena.2006.08.010

KIDRON, G., A. VONSHAK, I. DOR, S. BARINOVA \& A. ABELIOVICH. 2010. Properties and spatial distribution of microbiotic crusts in the Negev Desert, Israel. Catena 82: 92-101. https://doi.org/10.1016/j.catena.2010.05.006

KIDRON, G., A. YAIR, A. VONSHAK \& A. ABELIOVICH. 2003. Microbiotic crust control of runoff generation on sand dunes in the Negev Desert. Water Resour. Res. 39. https://doi.org/10.1029/2002WR001561

LAN, S., L. WU, D. ZHANG \& C. HU. 2012. Composition of photosynthetic organisms and diurnal changes of photosynthetic efficiency in algae and moss crusts. Plant Soil 351: 325-336. https://doi.org/10.1007/s11104-011-0966-9

MARTINEZ CARRETERO, E. \& A. DALMASSO. 1992. Litter yield in shrubs of Larrea in the Andean piedmont of Mendoza, Argentina. Vegetatio 101: 2133. https://doi.org/10.1007/BF00031912

NAGY M., A. PEREZ \& F. GARCIA-PICHEL. 2005. The prokaryotic diversity of biological soil crusts in the Sonoran Desert (organ Pipe Cactus National Monument, AZ). FEMS Microbiol. Ecol. 54: 233-245.

https://doi.org/10.1016/j.femsec.2005.03.011

NORTE, F. \& S. SIMONELLI. 2010. Características climáticas del piedemonte precordillerano del norte de Mendoza y sur de San Juan. En: VICH, A.I. \& M.E. GUDIÑO (eds.), Amenazas Naturales de Origen Hídrico en el centro-oeste árido de Argentina, pp. 91-109. Editorial Fundación Universidad Nacional de San Juan, San Juan.

NOY-MEIR, I. 1973. Desert ecosystems: environment and producers. Annu. Rev. Ecol. Syst. 4: 25-51. h t t ps://doi.org/10.1146/annurev. es.04.110173.000325

PASTRÁN, G., E. MARTINEZ CARRETERO, M. MAMANI, A. VICH \& V. SÁNCHEZ. 2011. Dinámica eólica e hídrica en el sistema de Médanos Grandes, SE de San Juan, Argentina. Multequina 20: $15-26$.
REGAIRAZ, A., G. SUVIRES \& W. SIMON.1987. Síntesis geomorfológica regional de la provincia de San Juan. República Argentina. En Actas III, X Congreso Geológico Argentino.

REGAIRAZ, M. 2000. Suelos de Mendoza. En: ABRAHAM E. \& F. RODRÍGUEZ MARTÍNEZ (eds.), Argentina. Recurso y problemas ambientales de la zona árida. Provincia de Mendoza, San Juan y La Rioja, pp. 59-62, Universidades y Centros de Investigación de la Región Andina Argentina.

RIPLEY B., B. VENABLES, D. BATES, K. HORNIK, A. GEBHARDT \& D. FIRTH, 2015. Package 'MASS'. Available at cran.r-project.org/web/ packages/MASS.

RODRÍGUEZ-CABALLERO, E., M. AGUILAR, Y. CANTÓN, S. CHAMIZO \& F. AGUILAR. 2015. Swelling of biocrusts upon wetting induces changes in surface micro-topography. Soil Biol. Biochem. 82: 107-111.

https://doi.org/10.1016/j.soilbio.2014.12.010

RODRÍGUEZ-CABALLERO, E., Y. CANTÓN \& V. JETTEN. 2015. Biological soil crust effects must be included to accurately model infiltration and erosion in drylands: an example from tabernas badlands. Geomorphology 241: 331-342.

https://doi.org/10.1016/j.geomorph.2015.03.042

RODRÍGUEZ-CABALLERO, E., Y. CANTÓN, S. CHAMIZO, A. AFANA \& A. SOLÉ-BENET. 2012. Effects of biological soil crusts on surface roughness and implications for runoff and erosion. Geomorphology 145-146: 81-89.

https://doi.org/10.1016/j.geomorph. 2011. 12.042

ROIG, F. 1976. Las comunidades vegetales del piedemonte de la precordillera de Mendoza. Ecosur 3: $1-45$.

SUVIRES, G. 1987. Geomorfología de la región centro sur de la provincia de San Juan, Argentina. En Revista simposio de teledetección. X Congreso Geológico Argentino.

WANG, L., G. ZHANG, L. ZHU \& H. WANG. 2017. Biocrust wetting induced change in soil surface roughness as influenced by biocrust type, coverage and wetting patterns. Geoderma 306: 1-9. https://doi.org/10.1016/j.geoderma.2017.06.032

WANG, Y., Y. ZHAO, C. YAO \& P. ZHANG. 2014. Surface roughness characteristics of biological soil crusts and its influencing factors in the Hilly Loess Plateau Region, China. Ying Yong Sheng Tai Xue Bao 25: 647-656. 


\section{A. L. Navas Romero et al. - Caracterización microtopográfica de las costras biológicas del suelo}

WILLIAMS, A., B. BUCK \& M. BEYENE. 2012. Biological soil crusts in the Mojave Desert, USA: micromorphology and pedogenesis. Soil Sci. Soc. Am. J. 76: 1685-1695. https://doi.org/10.2136/sssaj2012.0021

ZAADY, E., E.A. BEN-DAVID, Y. SHER, R. TZIRKIN \& A. NEJIDAT. 2010. Inferring Biological soil crust successional stage using combined PLFA, DGGE, Physical and biophysiological analyses. Soil Biol. Biochem. 42: 842-849.

https://doi.org/10.1016/j.soilbio.2010.02.002

ZHENG, Z., S. HE \& F. WU. 2014. Changes of soil surface roughness under water erosion process. Hydrol. Proces. 28: 3919-3929. https://doi.org/10.1002/hyp.9939 
